\title{
JAK PACHNIE TEL AWIW (I LÓDŹ)? O PRZESTRZENIACH OLFAKTORYCZNYCH W POEZJI RENATY JABLOŃSKIEJ
}

\author{
Beata TARNOWSKA (Uniwersytet Warmińsko-Mazurski)
}

Od lat 90. XX w. w naukach społeczno-humanistycznych narasta zainteresowanie rolą zmysłów w kształtowaniu obrazu otaczającej, zwłaszcza miejskiej, przestrzeni. Doświadczenia sensoryczne coraz częściej stają się przedmiotem badań nie tylko socjologów, antropologów i geografów, realizujących cele tzw. geografii humanistycznej ${ }^{1}$, ale także literaturoznawców. W dziedzinie literaturoznawstwa nowa perspektywa badawcza oznacza skupienie uwagi na literackich obrazach przestrzeni sensorycznych, rozumianych jako suma doznań wizualnych, audialnych, dotykowych, olfaktorycznych, a nawet smakowych ${ }^{2}$.

\footnotetext{
${ }^{1}$ Za jednego z prekursorów badań nad rolą zmysłów w kształtowaniu obrazu otaczającej przestrzeni można uznać niemieckiego socjologa i filozofa Georga Simmla, autora Socjologii (1908). Obok stworzonej przez Simmla socjologii zmysłów (Kelvin E. Y. Low), w tym obszarze badań wyłoniły się takie gałęzie wiedzy jak antropologia zmysłów (David Howes), studia zmysłowe (Paul Stoller), geografia sensoryczna (Paul Rodaway) czy proksemika (Edward T. Hall); zob. m.in.: P. Rodaway, Sensuous Geographies: Body, Sense and Place, London-New York 1994; Empire of the Senses: the Sensual Culture Reader, red. D. Howes, Oxford-New York 2006; C. Classen, D. Howes, A. Synnott, Aroma: the Cultural History of Smell, London-New York 2010; K. E. Y. Low, Scents and Scent-Sibilities: Smell and Everyday Life Experiences, Cambridge 2009; E. T. Hall, Ukryty wymiar, przeł. T. Hołówka, Warszawa 1976.

Miasto w perspektywie olfaktorycznej analizują także polscy socjologowie; zob. m.in.: M. S. Szczepański, W. Ślęzak-Tazbir, Miejskie pachnidto. Fragmentacja i prywatyzacja przestrzeni w perspektywie osmosocjologicznej, Studia Regionalne i Lokalne $2008 \mathrm{nr} 2$ (32), s. 18-40. Badaniem zmysłów w odniesieniu do otaczającej przestrzeni zajmuje się również psychologia wraz z jej subdyscypliną — neuropsychologią; zob. np.: E. Czerniawska, J. M. Czerniawska-Far, Psychologia węchu i pamięci węchowej, Warszawa 2007.

${ }^{2}$ Literacka geografia sensoryczna stanowi kategorię z zakresu nowej orientacji badawczej - geopoetyki, która rozpatruje interakcje zachodzące pomiędzy literaturą a przestrzenią geogra-
} 
Spośród przestrzeni odbieranych zmysłami to właśnie przestrzeń węchowa wydaje się najmniej dowartościowana przez zachodnich badaczy (w tym również literaturoznawców) $)^{3}$. Podczas gdy wzrok i słuch traktowane są jako podstawowe zmysły, służące człowiekowi do komunikowania się ze światem zewnętrznym, węch pozostaje niedoceniany ${ }^{4}$. Związane jest to po części z utrwalonym od czasów Arystotelesa przekonaniem o marginalności zmysłu powonienia w życiu człowieka ${ }^{5}$, a po części z preferencjami zachodniej kultury, która w miarę możliwości stara się wyrugować ze środowiska naturalne zapachy i zastąpić je sztucznymi ${ }^{6}$.

Miasto postrzegane w kontekście olfaktorycznym jedynie incydentalnie staje się przedmiotem badań literaturoznawczych ${ }^{7}$. Podobnie jak w badaniach o charakterze kulturoznawczym, antropologicznym czy przyrodniczym, w literaturoznawstwie przeważa przekonanie o nadrzędnej roli zmysłu wzroku w percepcji przestrzeni miejskiej. Coraz częściej jednak do głosu dochodzi pogląd, że doświadczanie miasta — tak jak każdej innej przestrzeni — jest zawsze multisensoryczne. Zdaniem amerykańskiego geografa Paula C. Adamsa, ,przemierzanie danego miejsca łączy się nieodmiennie $\mathrm{z}$ zaangażowaniem wzroku, słuchu, dotyku czy powonienia... zmysłu orientacji przestrzennej lub nawet smaku",

Miastem na poły europejskim, na poły orientalnym, o którym niemiecki kulturoznawca Joachim Schlör napisał, że „ma szczególny sposób pobudzania zmysłów: wy-

ficzną. Poetykę percepcyjną jako jedną z poetyk prezentacji miasta w literaturze wykorzystuje Elżbieta Rybicka w książce Modernizowanie miasta. Zarys problematyki urbanistycznej w nowoczesnej literaturze polskiej, Kraków 2003. Autorka skupia się jednakże na doświadczaniu miejskiego sensorium głównie za pomocą wzroku, a w mniejszym stopniu — słuchu i dotyku; por.: E. Rybicka, Geopoetyka. Przestrzeń i miejsce we wspótczesnych teoriach i praktykach literackich, Kraków 2014.

${ }^{3}$ Termin ,geografia zapachów”, za książką Geographie des odeurs, red. R. Dulau, J.-R. Pitte, Paryż 1998, wprowadziła do polskiego literaturoznawstwa Elżbieta Konończuk; zob.: E. Konończuk, Geografia zapachów wobec dyskursów humanistyki, Białostockie Studia Literaturoznawcze $2013 \mathrm{nr}$ 4, s. 53-61. Por.: J.-F. Staszak, W stronę geografii zapachów, thum. z franc. E. Konończuk, Białostockie Studia Literaturoznawcze 2013 nr 4, s. 41-51.

${ }^{4}$ Zob.: A. Marchlewska-Koj, Węch w życiu czlowieka, www.if-pan.krakow.pl/ptp/6.html (dostęp: lipiec 2015).

${ }^{5}$ Arystoteles uznawał węch za zmysł najbardziej ułomny spośród ludzkich zmysłów; zob.: Arystoteles, $O$ duszy, przeł. i oprac. P. Siwek, Warszawa 1988, s.100-102.

${ }^{6}$ Zob.: P. Rodaway, Sensuous Geographies, s. 74-81.

${ }^{7}$ Prace literaturoznawcze poświęcone przestrzeniom olfaktorycznym zazwyczaj nie odnoszą się do przestrzeni miejskiej; zob. m.in.: M. Bugajski, Jak pachnie rezeda?, Wrocław 2004; B. Mytych-Forajter, Czule punkty Grochowiaka. Szkice i interpretacje, Katowice 2010, s. 55-78 (rozdz.: Zapisane zapachy); M. Kokoszka, Leśmian i magia zapachów, Białostockie Studia Literaturoznawcze 2013 nr 4, s. 277-287. Por.: M. Michalska-Suchanek, Zapach jako kategoria poetyki. Na materiale nowelistów rosyjskich lat 80. XIX wieku, Slavia Orientalis $1995 \mathrm{nr} 4$, s. $527-542$.

${ }^{8}$ P. C. Adams, Peripatetic Imagery and Peripatetic Sense of Place, [w:] Textures of Place: Exploring Humanist Geographies, red. P. C. Adams, S. D. Hoelscher, K. E. Till, Minneapolis 2001, s. 188; cyt. za: S. Pink, Zwiedzanie miasta. Sensoryczny charakter więzi społecznych w etnograficznym procesie wytwarzania miejsca, przeł. M. Songin, Tematy z Szewskiej $2011 \mathrm{nr} 1$ (5), s. 139-140. 
ostrza nasz zmysł wzroku, słuchu, węchu i dotyku, a także rozpala naszą wyobraźnię", jest Tel Awiw. W literaturze tworzonej po polsku w Izraelu, a podejmującej przede wszystkim temat Zagłady i życia w diasporze, obraz Tel Awiwu nieczęsto jednak stanowi istotny punkt odniesienia. Pisarką, dla której twórczości percepcja telawiwskiej przestrzeni, także w jej aspekcie olfaktorycznym, stanowi szczególnie ważny motyw, jest Renata Jabłońska ${ }^{10}$. Chociaż wizerunek izraelskich miast można odnaleźć również w książkach innych pisarek polsko-izraelskich — zwłaszcza Marii Lewińskiej: Z moich trzech groszy reszta (Tel Awiw 1997), Emigracji dzień pierwszy (Warszawa 1999), Z maska na twarzy (Warszawa 2006); Haliny Aszkenazy-Engelhard: Warszawa Paryż - Tel Awiw (Warszawa 2004); Violi Wein: Jerozolimskie morze (Poznań 2011), w wierszach Idy Henefeld-Ron ${ }^{11}$, Jonatana Barkaia ${ }^{12}$, a nade wszystko w mikropowieści Leo Lipskiego Piotruś (Paryż 1960) — na tle polskiego pisarstwa w Izraelu tak znaczące, jak w twórczości Jabłońskiej, skupienie uwagi na przestrzeni kraju zamieszkania i „niewysuwanie wątków martyrologicznych" ${ }^{\text {13 }}$ wydaje się wyjątkowe.

Charakterystyczną cechą sposobu przedstawiania przez Renatę Jabłońską miejskiej przestrzeni - zarówno tej percypowanej „tu i teraz”, jak i przywoływanej w pamięci - jest sensualizm, niekiedy zauważany zresztą przez krytyków. O doświadczeniu sensorycznym, które w poezji Jabłońskiej „nierzadko bywa impulsem budzącym pamięć, rozsądek, zmysł realności" ${ }^{14}$ wspomina Zbigniew Chojnowski w recenzji tomiku Dotyk z 2012 r. Na pytania o naturę pamięci w utworach Jabłońskiej — „czy wspomnienie opiera się tylko na wrażeniach wzrokowych, czy także na słuchowych, dotykowych i zapachowych" - zwraca uwagę Jarosław Petrowicz ${ }^{15}$. Podobnie o predylekcji pisarki do odwoływania się do zmysłowości w sytuacji „nieustannego dialogu z otaczającą rzeczywistością” i ,penetrowania własnej pamięci” piszą Karolina Famulska $^{16}$, a także Lucyna Skompska. Zdaniem Skompskiej, przedstawione w poezji Renaty Jabłońskiej taktylne i termiczne wrażenia powiązane są ze stanem psychicznym pod-

9, ,...] this city has a special way of engaging all the senses: it heightens our seeing, hearing, smelling, feeling and touching, and also our imagination"; J. Schlör, Tel Aviv: From Dream to City, przeł. z niem. H. Atkins, London 1999, s. 9.

${ }^{10}$ Renata Jabłońska (ur. 1935 r. w Lodzi), do Izraela przybyła w 1957 r. wraz z tzw. aliją gomułkowską. W 1993 r. wydała w Izraelu tom opowiadań Kikar hamelech Albert [Plac króla Alberta], będący zbiorem publikowanych wcześniej w izraelskich pismach przekładów z języka polskiego. Natomiast pierwszy tomik poezji Ir zara [Obce miasto] — napisany w języku hebrajskim - opublikowała w 1999 r. Późniejsze książki, zarówno poetyckie, jak prozatorskie, ukazywały się w języku polskim, początkowo w wydawnictwie Akcenty (Tel Awiw), a następnie nakładem wydawnictw krajowych. W Polsce wydała następujące książki prozatorskie: Sen na cztery ręce (1995), Śpiew kameleona (2000), Niknace twarze (2004), Zimno, ciepto (2006), Przed odlotem (2009), Rozmowa z Losem (2011), Zabawy biatych plam (2012) oraz Fragmenty. Urywki wspomnień 1939-2009 (2014), a także tomiki wierszy: Chamsin (2002), Statyści (2008), i tyle (2010), inna (2015).

${ }^{11}$ I. Henefeld-Ron, Wczorajsze jutro: wiersze z Izraela, Londyn 1979 (wiersze: Widok na Hajfe, s. 18; Śmierć i narodziny obywatela, s. 21-23; W Jerozolimie, s. 74-77); por.: J. Winczakiewicz, Izrael w poezji polskiej. Antologia, Paryż 1958, s. 255-271.

${ }_{12}$ J. Barkai, Zatracona metropolia, przeł. V. Wein, Lublin 2013.

13 Z. Chojnowski, Marzycielka z charakterem, Nowe Książki 2013 nr 3, s. 84 [rec.: R. Jabłońska, Dotyk, Tel Awiw 2012].

${ }^{14}$ Tamże.

${ }^{15}$ J. Petrowicz, Fale tkliwości i żalu, Nowe Książki 2010 nr 9, s. 69 [rec.: R. Jabłońska, i tyle, Gołdap 2010].

${ }^{16}$ Jabłońska Renata, [w:] K. Famulska-Ciesielska, S. J. Żurek, Literatura polska w Izraelu. Leksykon, Kraków-Budapeszt 2012, s. 80. 
miotu wierszy — porte parole autorki — i pogłębiają jej wyrażane wielokroć poczucie obcości wobec otaczającej przestrzeni:

Obcość jest [...] odczuwana stale, na wszystkich poziomach istnienia: we wspomnieniach, w codziennych kontaktach z ludźmi, rzeczami, miastem. Poczucie obcości rodzi się już na granicy, która strzeże ciała - na skórze. Nieprzyjazne doznania zmysłowe przychodzą najczęściej ze strony powietrza: przykra wilgoć, pył niesiony przez wiatr wdzierają się w głąb ciała, w płuca, pokonują naturalne zapory ${ }^{17}$.

Z punktu widzenia Europejki, związanej kulturowo i emocjonalnie z rodzinnym kontynentem i z własną ojczyzną - Polską, Tel Awiw lat 50. jawił się jako „kompletny Orient”, „straszliwie obcy” i niebudzący zachwytu ${ }^{18}$. Utożsamiane z Lewantem, choć przecież w dużej mierze europejskie miasto, drażniło i odpychało ulicznym hałasem, odmienną mentalnością mieszkańców i współtworzącym jego olfaktoryczną mapę gorącym klimatem. Intensywności sensorycznych doznań sprzyjał fakt, że ich źródłem była przestrzeń nie tylko obca kulturowo, ale też percypowana po raz pierwszy. Zmysł powonienia - na co zwraca uwagę angielski geograf Paul Rodaway - tak bardzo bowiem przywyka do kodów węchowych, charakterystycznych dla przestrzeni własnej, że z czasem stają się one dla niego wręcz niezauważalne:

Zapachy, które odpychają albo ekscytują przybysza, przez osoby zamieszkujące daną okolicę mogą nie być po prostu zauważane czy wartościowane. Dopiero kiedy wyjedziemy z domu albo kiedy powrócimy do niego po kilku latach i znów poczujemy znane nam zapachy, wówczas to olfaktoryczne doświadczenie nabierze dla nas niezwykłej intensywności ${ }^{19}$.

Zjawisko to potwierdza tezę amerykańskiego etnologa Edwarda T. Halla, że „ludzie z odmiennych kręgów kulturowych nie tylko mówią odrębnymi językami, lecz również — co prawdopodobnie ważniejsze — przebywają $\mathrm{w}$ odrębnych rzeczywistościach zmysłowych" ${ }^{20}$.

Wspominając swoje pierwsze lata spędzone w Tel Awiwie, Jabłońska przywołuje przede wszystkim silne wrażenia sensoryczne, wpośród których dominowały wrażenia węchowe ${ }^{21}$ :

${ }^{17}$ L. Skompska, Za ruchoma przegroda, Tygiel Kultury 2002 nr 7-9, s. 179 [rec.: R. Jabłońska, Chamsin, Olsztyn 2002].

${ }^{18}$ Renata Jabłońska tak wspomina swoje pierwsze wrażenia po przyjeździe do Izraela: „przyjechałam niechętnie i wszystko mnie tutaj raziło. Raziło mnie słońce oślepiające, przyprawiające o bóle głowy, raził mnie brud, jakaś taka niechlujność, i te stragany, wrzaski, krzyki Orient kompletny! To wszystko było dla mnie tak straszliwie obce... [...] Każdy cię dotknie, każdy cię popchnie, nikt nie mówi przepraszam — byłam przerażona i zagubiona w tym lepkim tłumie"; Myśleć po polsku, myśleć po hebrajsku - z Renata Jabłońska rozmawia Beata Tarnowska, Fraza 2008 nr 3/4, s. 48-49.

${ }^{19}$ "The evocative smells which disturb or excite the visitor, may not be ordinarily noticed or valued by the resident or local. Only perhaps when traveling away from home or some years later when encountering once familiar smells again does the olfactory experience become again richly experienced"; P. Rodaway, Sensuous Geographies, s. 69-70; thum. własne.

${ }^{20}$ E. T. Hall, Ukryty wymiar, s. 27; por.: A. Wieczorkiewicz, Apetyt turysty. O doświadczaniu świata w podróży, Kraków 2012, s. 319-333.

${ }^{21}$ Intensywne doznania olfaktoryczne wspomina także Maria Lewińska, która przybyła do Izraela w 1958 r.: „Mocna kawa, zapach nagrzanej słońcem pożółkłej trawy, intensywna woń kwiatu pomarańczy - kwitnące gaje pomarańczowe czuje się - ich zapach rozchodzi się na kilka kilometrów, okupuje całe połacie nawet dalekie od jego gajów - mogłabym zamknąć oczy i po zapachu poznać, że to Izrael”. Obok woni pomarańczy, autorka za dominującą nutę pejzażu 
w południowym Tel Awiwie, na placu przy centralnej stacji autobusowej, dostawałam w owych latach zawrotów głowy i mdłości, tak działały na mnie zapachy falafla, przypalonego oleju, wrzaski sprzedawców owoców, ciuchów i Bóg wie czego jeszcze... I te stare, duszne, rozgrzane autobusy, i spoceni, zziajani ludzie, pchający się do środka ${ }^{22}$.

„Silna sensoryczna stymulacja” jest — zdaniem Edwarda T. Halla — cechą charakterystyczną kultury Bliskiego Wschodu, zwłaszcza w porównaniu z ascetyczną zapachowo północną Europą oraz północną Ameryką. Pisząc o składnikach sensorycznych tej barwnej sensualnie kultury, Hall na pierwszym miejscu wymienia zapach, który przybyszów ze świata zachodniego wręcz „przytłacza i przygniata”, a dopiero potem „,przepychanie się i ścisk w miejscach publicznych” oraz „duży hałas”,23.

Węch, który stanowi, mówiąc słowami niemieckiego socjologa Georga Simmla, „,najbardziej intymny rodzaj percepcji”, gdyż „wnika niejako do rdzenia naszej zmysłowej istoty” i jest ,z góry nastawiony na większą bliskość niż wzrok i słuch”, charakteryzuje również to, że jest on zmysłem dysocjacyjnym, przekazującym „,nieskończenie więcej bodźców odpychających niż pociągających", a ,jego decyzje mają w sobie coś radykalnego i nieodwołalnego, co trudno przezwyciężyć decyzjami innych zmysłów"24. W ,telawiwskich” wierszach Renaty Jabłońskiej zapach potu, który intensywnieje latem, mdlący aromat sprzedawanych na ulicy orientalnych potraw, zapach suchego wiatru znad pustyni, potęgowana przez upał woń rozgrzanego asfaltu i samochodowych spalin, a nawet fetor padliny — stawały się podstawowym i w dolegliwy sposób odczuwanym kodem zapachowym Tel Awiwu:

$$
\begin{aligned}
& \text { niebo nad miastem }[\ldots] \text { dyszy } \\
& \text { upałem kurzem spalinami } \\
& {[\ldots]} \\
& \text { cuchnie zgnilizną padliną } \\
& \text { przypalonym thuszczem } \\
& \text { tanich knajp it } 11 ; \text { blękit }^{25}
\end{aligned}
$$

zapachowego Tel Awiwu uznaje również zapach morza i niesiony wiatrem zapach wodorostów; M. Lewińska, Emigracji dzień pierwszy, Warszawa 1999, s. 82, 49, 59. Por. późniejszą o trzydzieści lat relację Mariana Bizana: „To był październikowy przedświt 1988 roku, kiedy po raz pierwszy lądowałem w Izraelu. [...] Mimo wczesnej pory ciepły, wilgotny i łagodny powiew wiatru z różnych stron, również od morza, niósł z sobą zapachy — lawendy, rozmarynu, eukaliptusów, palm"; M. Bizan, Zapachy miast, Zeszyty Literackie 2010 nr 4, s. 130-133.

${ }^{22}$ Myśleć po polsku, myśleć po hebrajsku, s. 49.

${ }^{23}$ Zob.: E. T. Hall, Ukryty wymiar, s. 219.

${ }^{24}$ G. Simmel, Socjologia zmystów, [w:] tegoż, Most i drzwi: wybór esejów, przeł. M. Łukasiewicz, Warszawa 2006, s. 202-203. W odróżnieniu od innych wrażeń, zapach ma tę cechę, że nie można od niego uciec. O perswazyjnej sile zapachu pisze Patrick Süskind, autor pochodzącej z 1985 r. powieści Pachnidło: „Ludzie bowiem mogą zamykać oczy na wielkość, na grozę, na piękno, i mogą zamykać uszy na melodie albo bałamutne słowa. Ale nie mogą uciec przed zapachem. Zapach bowiem jest bratem oddechu. Zapach wnika do ludzkiego wnętrza wraz z oddechem i ludzie nie mogą się przed nim obronić, jeżeli chcą żyć. I zapach idzie prosto do serc i tam w sposób kategoryczny rozstrzyga o skłonności lub pogardzie, odrazie lub ochocie, miłości lub nienawiści”; P. Süskind, Pachnidło, z niem. przeł. M. Łukasiewicz, Warszawa 2015, s. 157.

${ }^{25}$ Cytowane fragmenty wierszy pochodzą z następujących tomików poetyckich R. Jabłońskiej: Inny wymiar, Tel Awiw 2001 (dalej w skrócie: Iw); Statyści, Gołdap 2008 (St); i tyle, wiersze wybrane, wybór, oprac. i posłowie B. Tarnowska, Gołdap 2010 (it); Dotyk, Tel Awiw 2012 (D); Skok, Tel Awiw 2013 (S); inna, Gołdap 2015 (in). Cyfra podana obok skrótu oznacza numer strony. 
brud i smrodem dysząca

lepkość sierpniowej nocy

$[\ldots]$

it 21; powrót noca

zapach spalin

rozgrzanego asfaltu

smoły

Iw 13; obraza

$[\ldots]$

ulewa zamienia jezdnie w kanały

które bulgocą cuchną szarożółtą cieczą

St 46; burza

Wrażenia olfaktoryczne, które ulegają intensyfikacji w gorącym klimacie, powodując fizyczny i psychiczny dyskomfort, stają się jednocześnie ważnym elementem tworzącym nastrój utworów, a niekiedy wręcz ich semantyczno-nastrojową dominantą. Jak pisze Mirosława Michalska-Suchanek, ,nie zauważony jakby zostaje problem nastrojotwórczego oddziaływania zapachów. Tymczasem wrażenia węchowe posiadają często nie uświadomione, aczkolwiek istotne wartości emocjonalne" ${ }^{\text {26 }}$.

Nastrój niepokoju i przygnębienia nierzadko łączy się w wierszach Jabłońskiej z poetyckimi obrazami chamsinu - gorącego, porywistego wiatru znad pustyni, który niosąc wielkie ilości pyłu i piasku, podnosi temperaturę powietrza nawet do około $40^{\circ} \mathrm{C}$. Na pytanie o zapach chamsinu, Renata Jabłońska odpowiada:

Są różne chamsiny: bardzo gorąco i bardzo sucho w całym kraju, z pędzonym wiatrem pyłem pustynnym - to ma zapach suchy, drażniący gardło i nos; chamsiny, gdy na południu jest bardzo gorąco i sucho, a na równinie nadmorskiej bardzo gorąco i parno (to najgorsza pogoda) - wtedy w zaułkach śmierdzi szczyną, zapach spalin wzmaga się, czuć pot, padlinę i przypalone żarło....

Nad morzem chamsin czasem miesza się z mokrym nadmorskim powietrzem i wtedy jest lepko i paskudnie, czasem smrodliwie (gnijące resztki, padlina...). Pochamsinowe powietrze, stosunkowo wilgotne, czasem pachnie świeżością roślinności — tak wiosną, jak i jesienią. ${ }^{27}$.

Chociaż w wierszach Jabłońskiej nie pojawia się bezpośrednio próba określenia zapachu powietrza w czasie, kiedy wieje chamsin, niemniej przywołanie związanych z tym zjawiskiem atmosferycznym konkretnych doznań somatycznych oraz stanów emocjonalnych podmiotu sugeruje jakby pewne, wewnętrznie zakodowane jakości zapachowe. Zależnie od nastroju podmiotu, suchy zapach tego wiatru — podobnie jak wilgotna woń powietrza - mogą być przy tym wartościowane dodatnio lub ujemnie ${ }^{28}$ :

czas się rozłazi jak fale piasku omiatane pustynnym wiatrem

${ }^{26}$ M. Michalska-Suchanek, Zapach jako kategoria poetyki, s. 527.

${ }^{27} \mathrm{Z}$ listów mailowych do Beaty Tarnowskiej 12.06.2015 oraz 7.11.2015.

${ }^{28}$ Por.: „Przyjemny lub nieprzyjemny zapach wody i wilgoci w tekstach języka polskiego nie jest zjawiskiem zobiektywizowanym w tym sensie, jak na przykład zapach kwiatów, który $\mathrm{w}$ zasadzie charakteryzowany jest dodatnio. Wilgotna woń w zależności od potrzeb nadawcy może oddawać jego pozytywne bądź negatywne emocje i do wyzwalania takich emocji u odbiorcy może służyć"; M. Bugajski, Jak pachnie rezeda?, s. 188. 
[...]

suche powietrze drażni nozdrza

[...]

gorący oddech wiatru niesie niepokój

spragniona ziemia milczy

suche wargi poruszają się $\mathrm{z}$ trudem

[...]

it 50-51; chamsin

[...]

noc duszna jak w schronie

zasypanym gruzem

z którego wydostaję się

pełznąc powoli przez sen

rankiem wilgotny powiew

niepewne siebie słońce

i gołębie na balkonie

ogłaszają że życie trwa

it 52; osad

[...]

dzień jest słoneczny suchy

już pachnie wiosną i chamsinem

in 52; w kawiarni

mokry wiatr powietrze

ciężkie nasycone wilgotnym

kurzem i spalinami

in 9 ; deszcz

w lepkim zimnym powietrzu

wyliczanka krzywd bierze górę

it $14 ; m \dot{a} a w k a$

Wedle opinii francuskiego geografa Jeana-Françoisa Staszaka, ,zapach nigdy nie jest neutralny, jest ładny albo brzydki, przyjemny albo brzydki”. Badacz ten zwraca przy tym uwagę, że:

ocena zapachów nie jest niezależna, lecz uwarunkowana kulturowo. Jeśli zapachy są rozpoznawane jako ładne lub brzydkie, to mamy do czynienia z pewnym fenomenem społecznym. W istocie wydaje się bardzo prawdopodobne, że zapach nie jest ani ładny, ani brzydki sam w sobie - na mocy kilku wewnętrznych właściwości - w zasięgu uniwersalnym, który uzasadnia sądy o wartościach transkulturowych. Przeciwnie, zapachy są oceniane według klucza o charakterze kulturowym ${ }^{29}$.

Zapachy, jakie pojawiają się w ,telawiwskich” wierszach Jabłońskiej, są traktowane najczęściej jako egzotyczne i zarazem silnie spolaryzowane: odpychają i powoduja uczucie wstrętu albo wręcz przeciwnie - budzą przyjemność, a nawet ekstazę. Do drugiej kategorii należą wrażenia węchowe wywołujące skojarzenia z utrwaloną w zachodniej kulturze arkadyjską wersją Wschodu; natomiast do pierwszej — te, które wyzwalając doznania o charakterze pejoratywnym, współtworzą polemiczną wobec

\footnotetext{
${ }^{29}$ J.-F. Staszak, W stronę geografii zapachów, s. 44.
} 
niej wizję Orientu/Lewantu jako infernum ${ }^{30}$. Tę silną polaryzację potwierdza przywoływany $\mathrm{w}$ wierszach Jabłońskiej kod zapachowy telawiwskich ulic: niemiłe wonie rozmaitej proweniencji zagłuszają zapachy morskiej bryzy, kwitnących drzew i krzewów $^{31}$, a także ożywczy ,zapach miasta po wiosennych deszczach — aromat świeżej zieleni, mokrej trawy...,32. Za najbardziej ekscytujący i jednocześnie egzotyczny poetka uznała jednak zapach etroga:

[...] ja już jestem tutejsza, ale kwitnące hibiskusy, bugenwille, poncjany, efitny, dżakarandy - wciąż wydają mi się egzotyczne, po tylu latach... [...]. Nigdy też nie zapomnę drogi do wsi, w której mieszkała moja kuzynka. Po jednej stronie była plantacja etrogów (ten owoc wygląda trochę jak cytryna i jest jednym z trzech owoców „kultowych” w czasie święta Sukkot). Kiedy etrog zakwita, jego zapach jest upajający, rajski po pro$\mathrm{stu}^{33}$.

Zapach jako element nastrojotwórczy pojawia się często w wierszach opisujących wiosnę w Tel Awiwie:

$$
\begin{aligned}
& \text { po deszczowych zimnych dniach } \\
& \text { pogoda słoneczna lekki wiatr } \\
& \text { od morza i zapach wiosny } \\
& \text { w powietrzu } \\
& \text { gałęzie drzew za oknem tańczą } \\
& \text { razem ze mną a wróbel na parapecie } \\
& \text { dziobie ziarna zataczając kręgi } \\
& \text { in } 66 \text {; dobry dzień }
\end{aligned}
$$

W wierszu wiosna II przyjemny zapach kwitnących drzew izdarechet podnosi na duchu i pobudza do życia:

$$
\begin{aligned}
& \text { na mojej ulicy } \\
& \text { znów się panoszy } \\
& \text { zapach izdarechet } \\
& \text { to znaczy że minął rok } \\
& \text { wiosna hojną ręką } \\
& \text { obdarowuje kwiatami } \\
& \text { krzewy i drzewa i wzgórza } \\
& \text { nawet pustynię ozdabia } \\
& \text { wzbudza nadzieje } \\
& \text { usypia świadomość } \\
& \text { czaruje barwną mgiełką }
\end{aligned}
$$

${ }^{30}$ Por.: S. Burkot, Polskie podróżopisarstwo romantyczne, Warszawa 1988 (rozdz.: Le génie de l'Orient), s. 41-121; por.: D. Kulczycka, Obraz Ziemi Świętej w prozie polskiej doby romantyzmu, Zielona Góra 2012; taż, W stronę Orientu: polscy i francuscy romantycy o Bliskim Wschodzie, Zielona Góra 2012; Ziemia Święta w dobie romantyzmu: antologia, oprac. D. Kulczycka, Zielona Góra 2013; E. Kuźma, Mit Orientu i kultury Zachodu w literaturze XIX i XX wieku, Szczecin 1980; E. W. Said, Orientalizm, przeł. W. Kalinowski, wstęp Z. Żygulski, Warszawa 1991

${ }^{31}$ Jak pisze Renata Jabłońska, „od lutego do kwietnia jest masa kwiatów. Jesienią też. Niektóre kwiaty rosną cały rok”. „Wiosną pachnie izdarechet, efitna, różne inne kwiaty. Dżakaranda chyba też. I oleandry. Hibiskusy raczej nie pachną. Najsilniej (po izdarechet) pachnie efitna". $\mathrm{Z}$ listu mailowego do autorki, 15.06.2015.

${ }^{32} \mathrm{Z}$ listu mailowego do autorki, 12.06.2015.

${ }^{33}$ Myśleć po polsku, myśleć po hebrajsku, s. 49. 


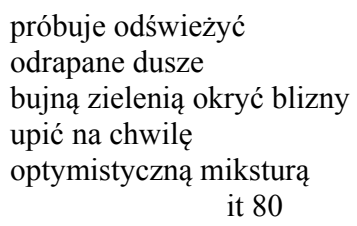

Zapach izdarechet wyzwala pozytywne emocje również $\mathrm{z}$ tego powodu, że przypomina zapamiętaną z dziecięcych lat woń swojskiej czeremchy ${ }^{34}$. Zestawienie aromatu obu kwitnących roślin, percypowanego „tu i teraz”, oraz wydobytego ze zmysłowej pamięci, wywołuje zapachową nostalgię i uruchamia poczucie podwójnego zakorzenienia:

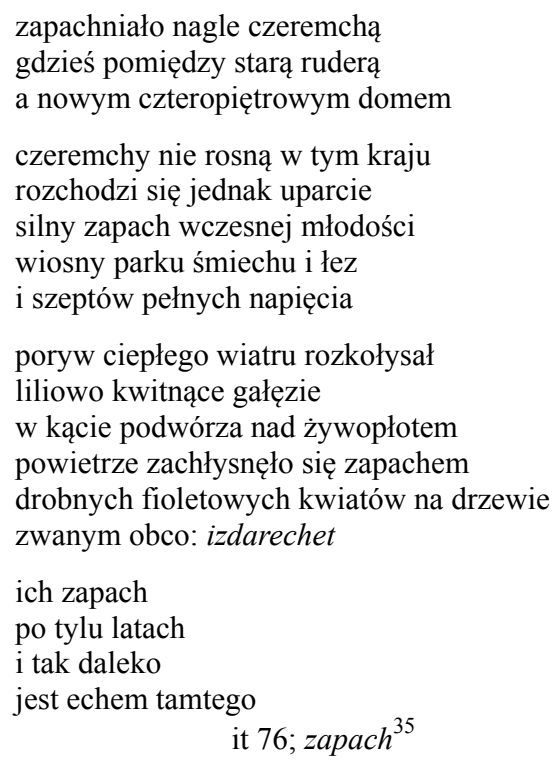

Podobne asocjacje ewokuje zapach telawiwskiej ulicy, obmytej pierwszym jesiennym deszczem. Zapach parującej ziemi nie tylko przykrywa ,przedwczorajsze” wyziewy spalin, ale również przenosi podmiot w odległy czas i miejsce:

${ }^{34}$ Próbując opisać zapach izdarechet, Jabłońska dopowiada: „Izdarechet nie pachnie dosłownie jak czeremcha, ale coś jednak jest na rzeczy (i nasilenie zapachu). Inne zapachy nie przypominają polskich pachnących kwiatów. Efitna może dalekim bardzo echem przypominać akację... Ale może się mylę"; z listu mailowego do autorki, 14.06.2015. Mocny, gorzki i jednocześnie świeży zapach czeremchy przywoływany bywał w poezji młodopolskiej; zob.: M. Bugajski, Jak pachnie rezeda?, s. 172.

${ }^{35}$ Por.: ,bugenwille dżakarandy / hibiskusy efitny oleandry / jak to wszystko kwitnie / egzotycznie / a mnie się śnią pierwiosnki / i niezapominajki i kasztany / i bzy i wiosennych zadurzeń / śmiechy i łzy / z dawno minionej / młodości" (it 64; kwiaty). Zestawianie obrazów roślin należących do dwóch przestrzeni odległych geograficznie świadczy tutaj nie tyle o prowizorycznym zakorzenieniu poetki w nowej ojczyźnie, co o jej rozdwojonym poczuciu przynależności, gdyż — jak mówi — „Nie można żyć bezkarnie w jakimś kraju, cieszyć się jego przyrodą, nasiąkać jego kultura, mieć tam przyjaciół, uczyć się, studiować, i naraz, mając 21 lat, wyjechać na stałe nie tylko do innego państwa, ale z Europy do Azji..."; Myśleć po polsku, myśleć po hebrajsku, s. 49. 


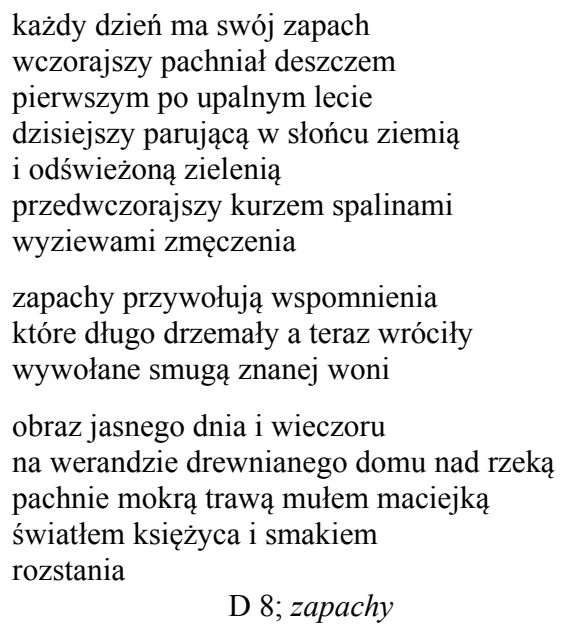

Percepcja olfaktoryczna, łącząca przestrzeń i czas, wynika z faktu, że — jak pisze Edward T. Hall — „Zapach wywołuje [...] wspomnienie znacznie głębsze niż obraz czy dźwięk”36. Przyczyny, dla których ,pamięć zapachów potrafi pozostać nietknięta nawet przez lata" ${ }^{37}$, wyjaśnia natomiast socjolog Kelvin E. Y. Low:

Pamięć zapachów jest mniej dotknięta upływem czasu niż wspomnienia wizualne i słuchowe [...]. Raz zapamiętane, zapachy rzadko, jeśli w ogóle, są zapomniane. Wedle badaczy dzieje się tak, ponieważ rozbudzają one podstawowe emocje. Zapachy same w sobie mogą nie mieć znaczenia, ale stają się powiązane $z$, uczuciami”. Nic nie może przywołać wspomnienia tak szybko i tak pewnie jak zapach ${ }^{38}$.

Pejzaż zapachowy ${ }^{39}$ miasta, w dużej mierze konstytuujący jego tożsamość, nie jest jednak niezmienny, dany raz na zawsze. Zdaniem kanadyjskiego antropologa, Davida Howesa:

Zapachy istnieją $\mathrm{w}$ czasie $\mathrm{i}$ zmieniają się wraz $\mathrm{z}$ upływem czasu, tak jak istnieją i zmieniają się w przestrzeni [...]. Taki „pejzaż zapachowy” nie stanowi oczywiście sztywnej konstrukcji, ale jest raczej płynną strukturą, zmieniającą się w zależności od warunków atmosferycznych ${ }^{40}$.

${ }^{36}$ E. T. Hall, Ukryty wymiar, s. 82.

${ }^{37}$ K. E. Y. Low, Olfactive Frames of Remembering: Notes on the Smells of Memories, Singapore 2007, http://socioblogsg.files.wordpress.com/2007/02/lowwp 179.pdf; (dostęp: lipiec 2015).

38 "Odour memory is less influenced by the passage of time than auditory and visual memories. [...] Once remembered, smells are rarely if ever forgotten. Scientists believe this is because odours stir basic emotions. They may have no meaning themselves but they become associated with «feelings». Nothing can recall a memory as quickly and as surely as an odour"; tamże, s. 7. Zdaniem psycholożek Ewy Czerniawskiej i Joanny Czerniawskiej-Far: „Wspomnienia wydobyte dzięki zapachom różnią się jakościowo i ilościowo od wspomnień wydobytych dzięki innym wskazówkom. Cechuje je silniejsze nasycenie emocjonalne oraz istotnie większa liczba przytaczanych szczegółów". E. Czerniawska, J. M. Czerniawska-Far, Psychologia węchu, s. 104-105.

${ }^{39}$ Termin za: D. Porteous, Smellscape, [w:] The Smell Culture Reader, red. J. Drobnick, Oxford-New York 2006, s. 89-106.

40 "Just as odours exist in time and change with time, so do they exist and change within space. [...] Such a «smellscape» is obviously not a fixed structure, but rather a highly fluid 
Obok pory dnia i roku, mapę olfaktoryczną miast kształtuje także — dodajmy — wiele innych, zmiennych w czasie czynników, takich jak pora dnia i roku, stopień zanieczyszczenia środowiska, obecność terenów zielonych, zamożność mieszkańców ${ }^{41}$.

W swojej późnej poezji Renata Jabłońska wielokrotnie wyraża nostalgię za dawnym Tel Awiwem, mniejszym i biedniejszym, ale nieodartym jeszcze tak bardzo z ciepła międzyludzkich więzi ${ }^{42}$ i nieprzypominającym — także pod względem bodźców zapachowych — wielkich zachodnich metropolii. Jak wspomina:

Dawniej było dużo kiosków z tanimi potrawami — falaflem, humusem, frytkami, które często przygotowywano na przypalonym oleju, miasto było biedniejsze, autobusy nieklimatyzowane, więc ludzie się pocili.... Teraz ludzie bardziej dbają o higienę, zapachy są zatem często ,perfumowane”. A w klimatyzowanych biurach i innych pomieszczeniach panuje taki suchy zapach ${ }^{43}$.

Nowoczesność oznacza próbę wyrugowania zapachów: wraz z rozbudową miasta i pojawianiem się coraz liczniejszych wieżowców, banków oraz centrów handlowych, Tel Awiw stopniowo pozbywa się dawnych woni. Eliminując naturalne zapachy i zastępując je zapachami syntetycznymi, pod względem mapy olfaktorycznej to miasto coraz bardziej upodabnia się do innych miejskich aglomeracji ${ }^{44}$.

W poezji Jabłońskiej Tel Awiw z dawnych lat nieodmiennie wywołuje nostalgię. W wierszu budynek opisany został, na przykład, „ładny, półokrągły, stary” dom, w którym kiedyś „,na parterze pachniała przyprawami / węgierska restauracja”, a teraz:

\author{
[...] połyskuje bielą nowy \\ półokrągły dom w niczym poza tym \\ nieprzypominający tamtego \\ przez szklane szerokie drzwi widać \\ wielkie lobby $z$ fontanną \\ naokoło korytarze z zamkniętymi \\ drzwiami niewiadomych pomieszczeń \\ nie ma tam żadnego szyldu i nigdy \\ nie widać w środku ludzi \\ może za zamkniętymi drzwiami \\ snują się duchy dawnych \\ mieszkańców?
}

D $50-51$

Charakterystyczna dla nowych czasów aura sterylności, która sugeruje bezwonną czystość, nie ominęła również znajomej apteki, dawniej pachnącej ziołami i walerianą:

pattern that can shift and change according to atmospheric conditions"; C. Classen, D. Howes, A. Synnott, Aroma: the Cultural History of Smell..., s. 97.

${ }^{41}$ Por.: M. S. Szczepański, W. Ślęzak-Tazbir, Miejskie pachnidło, s. 33 n.

${ }^{42}$ Por.: „W nowych dzielnicach miasta, nawet teraz, gdy budują ładniej i nie tak jednolicie jak kiedyś, nie czuję się «zadomowiona». A ta masa wieżowców rosnących jak grzyby po deszczu trochę mnie przeraża. Wydaje mi się, że ludzie mieszkający w takich, ekskluzywnych oczywiście, mrówkowcach, muszą być jacyś «przyszłościowo nastawieni», mało uczuciowi”; R. Jabłońska, Fragmenty. Urywki wspomnień 1939-2009, Lublin 2014, s. 132.

${ }^{43} \mathrm{Z}$ listu mailowego do autorki, 12.06.2015.

${ }^{44}$ Zdaniem Paula Rodawaya, kultura zachodnia nie przywiązuje dużej wagi do zapachów, a zatem w krajach zachodnich doświadczenia olfaktoryczne traktowane są jako drugorzędne, a zapachy, jakie się preferuje, są na ogół mniej intensywne i sztuczne; P. Rodaway, Sensuous Geographies, s. 75, 81 . 


$$
\begin{aligned}
& \text { zniknęły małe sklepiki } \\
& \text { spożywcze pasmanteria kiosk } \\
& \text { ale na rogu widzę znajomą } \\
& \text { aptekę z tą samą wystawą } \\
& \text { i szyldem: „Apteka } \\
& \text { Lekarstwo” i to mnie } \\
& \text { rozśmiesza jak kiedyś } \\
& \text { dawniej była tam dębowa lada } \\
& \text { i szafki na leki z szlifowanym } \\
& \text { szkłem drzwiczek pachniało } \\
& \text { ziołami i mieszanymi lekami } \\
& \text { wchodzę do środka - biało } \\
& \text { ani śladu dębowej lady i szaf } \\
& \text { nie ma zapachu waleriany } \\
& \text { czy innych mikstur } \\
& \text { na białych półkach stoją gotowe } \\
& \text { leki w kartonowych pudełkach } \\
& \text { na ladzie reklamy różnych firm } \\
& \text { kupuję pastę do zębów wychodzę } \\
& \text { i nagle słyszę dzwonek u drzwi } \\
& \text { ale to nie ten miedziany dźwięk } \\
& \text { jak kiedyś ten jest elektryczny } \\
& \text { in 53; lekarstwo }
\end{aligned}
$$

Bodźce zapachowe, jakie w wierszach Jabłońskiej łạczą się ze wspomnieniami dawnego Tel Awiwu, a także rodzinnej, powojennej Łodzi ${ }^{45}$, skorelowane są z wrażeniami smakowymi ${ }^{46}$. „Zapach i smak bowiem — jak pisze Paul Rodaway — łączą się ze sobą do tego stopnia, że intensywny zapach odbieramy nie tylko zmysłem powonienia, ale też smakiem"47.

Podobnie jak zapachy, smaki mogą stać się impulsem, wyzwalającym wspomnienia trwalsze od wspomnień wizualnych i słuchowych, ,trwające czasem przez całe życie"48. Jak zauważa rumuńska filozofka Mădălina Diaconu:

Już niekompletność dotykowych, węchowych i smakowych przedstawień sugeruje znaczenie czasu w doświadczaniu tych zmysłów. Wspomnienie dotyku, zapachu i smaku

${ }^{45}$ Zdaniem Jerzego Jarzębskiego, dzisiejsza Łódź nieco przypomina Tel Awiw, gdyż jest miastem ,podobnie niespójnym w centrum”, ,gdzie małe stare domki i wąskie uliczki przeplatają się z przebitymi przez gęstwę przedwojennej zabudowy szerokimi arteriami i zwalistymi blokami”; J. Jarzębski, Łódź-Tel Awiw, Tygodnik Powszechny 2002 nr 34, www.tygodnik. com.pl/numer/277234/jarzebski.html (dostęp: listopad 2015).

${ }^{46}$ Analogię pomiędzy zmysłem powonienia a zmysłem smaku spostrzegł już Arystoteles, który zauważył zarazem, ,że zmysł smaku jest w nas bardziej doskonały [od powonienia], bo jest pewnym rodzajem dotyku — a ten jest u człowieka najdoskonalszy"; Arystoteles, $O$ duszy, s. 100.

47 "the close association of smell and taste, [...] that we feel the taste of a strong odour as much as we smell it, and strong smells seem almost tangible to us, as if we could «touch» them. The chemical basis of oflaction makes it a far more direct sensuous geography than sight, and perhaps also hearing"; P. Rodaway, Sensuous Geographies, s. 67.

48 "the olfactory and gustatory memories are very persistent and can sometimes last an entire life"; M. Diaconu, The Rebellion of the "Lower" Senses: A Phenomenological Aesthetics of Touch, Smell, and Taste, www.o-p-o.net/essays/DiaconuArticle.pdf, s. 3 (dostęp: lipiec 2015). 
jest przeważnie niewerbalne i rozproszone, przepojone afektywnymi wrażeniami i synestezjami. Przypominamy sobie zapachy i smaki spontanicznie i odruchowo [...] w spontanicznym wspominaniu powraca sama przeszłość [...]. Pojedyncza scena skupia esencję czyjegoś życia, czas już nie płynie, tylko w jakiś sposób zostaje przekroczony ${ }^{49}$.

Podczas gdy Tel Awiw końca lat 50. kojarzy się ze smakiem zimnych arbuzów (S 33) i zapachem przypraw z węgierskiej restauracji (D 50), na sensoryczny, utrwalony w pamięci poetki pejzaż powojennej Łodzi ${ }^{50}$ składają się, obok niemiłych woni zaniedbanych podwórek i ulic, zapachy czeremchy, akacji, bzu, konwalii oraz ściśle powiązane $\mathrm{z}$ topografią tego miasta smaki rurek z kremem i śmietankowych lodów w waflach:

\author{
$[\ldots]$ \\ rurka z kremem od Granowskiej \\ przy Narutowicza róg Piotrkowskiej \\ albo śmietankowe lody w kwadratowych \\ waflach z wózka ulicznego sprzedawcy \\ naprzeciwko przed „Delfinem” \\ bełkot pijaków i szczanie na odrapany \\ czarny mur narożnej kamienicy \\ $[\ldots]$ \\ wiosną w parkach kwitnące akacje \\ kasztany i bez i sprzedawane na ulicy \\ bukieciki konwalii \\ pachniały inną rzeczywistością \\ S 32; dawna Łódź
}

Rodzinna Łódź, która podczas wojennej odysei wydawała się Renacie Jabłońskiej utraconym rajem, po wojnie była przez nią postrzegana jako miasto oferujące bogactwo zmysłowych, w tym także wizualnych i smakowych, bodźców:

Lubiłam łazić po mieście. Pamiętając jeszcze wojenny głód, zatrzymywałam się przed garmażerią na rogu Piotrkowskiej i Zielonej i przyglądałam się smakołykom. Ogląda-

49 "Already the incompleteness of the haptic, olfactory, and gustatory representations suggests the importance of time in the experience of these senses. The memory of haptic qualities, odors, and flavors is mostly non-verbal and diffuse, imbued with affective impressions and synaesthesias. We recollect odors and flavors spontaneously and involuntarily [...] in spontaneous recollection the past itself returns [...]. A single scene concentrates one's life essence, time flows no more, but is somehow overcome". M. Diaconu, The Rebellion of the "Lower" Senses, s. 5.

${ }^{50} \mathrm{Na}$ temat obrazu Łodzi w literaturze zob. m.in.: Lódź, która przeminęła w publicystyce i prozie (antologia), red. P. Boczkowski, Łódź 2008; K. Kołodziej, Obraz Łodzi w piśmiennictwie pozytywistyczno-młodopolskim, Łódź 2009. Zapachowy pejzaż współczesnej Łodzi, a zwłaszcza takich jej stref, jak Rynek Bałucki, hipermarket, główna ulica miasta czy podwórko jednej z kamienic w centrum, przedstawia Aleksandra Krupa w artykule Aromaty $i$ smrody. Olfaktoryczny pejzaż miasta, [w:] Lato w mieście. Różne oblicza kultury, red. R. Godula-Węcławowicz, WarszawaKraków 2010, s. 163-179. Por. opis zapachów łódzkiej ulicy zawarty w tekście Krystyny Piątkowskiej, W zasiegu wzroku, stuchu lub węchu. O pewnych faktach społeczno-kulturowych z europejskiej historii, antropologicznych konstatacjach oraz impresjach z kultury lokalnej dużego, polskiego miasta, czyli o kodach niezsynchronizowanych, s. 101, zew.info.pl/files/piatkowska17.pdf (dostęp: maj 2015). 
łam też wystawę małego sklepiku pani Andrzejewskiej przy Narutowicza 3, gdzie leżały ładne bluzeczki i barwne drewniane korale. W księgarni na Piotrkowskiej oglądałam książki i stare sztychy. W cukierni Granowskiej fundowałam sobie chrupiącą rurkę $\mathrm{z}_{\text {kremem }}{ }^{51}$.

W pejzażu olfaktorycznym Łodzi, która — jak wspomina Jabłońska — „śmierdziała dawno temu ściekami fabrycznymi, kurzem, biedą w robotniczych dzielnicach domy miały okropne podwórka i często cuchnące ubikacje",52, ważną nutę zapachową stanowią również wonie natury ${ }^{53}$, gdyż „Łódź — zdaniem antropolożki Ingi B. Kuźmy — jest jednym z najbardziej zielonych miast w Polsce. W obrębie miasta zachowane są dwa rezerwaty leśne, w tym ścisły, jak Polesie Konstatynowskie [...] i Las Łagiewnicki. [...] Istnieje także kilka innych lasów i uroczysk (jak Lublinek czy Ruda-Popioły) oraz wiele parków" ${ }^{\text {"54. }}$.

W wierszu wiatr, jednym z niewielu utworów napisanych przez Jabłońską w dzisiejszej Łodzi, dominantę semantyczno-emocjonalną stanowi zapach jesiennych liści:

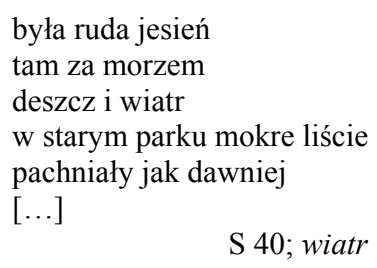

Intymny związek poetki z Łodzią wyrażają także wiersze, przywołujące utkaną z zapachów historię jej życia. W wierszu dawno szczęśliwe przedwojenne lata ożywają dzięki skojarzonym z nimi ekskluzywnym woniom, które ewokują dostatek i poczucie bezpieczeństwa ${ }^{55}$ :

$$
\begin{aligned}
& {[\ldots]} \\
& \text { dawno bardzo dawno temu } \\
& \text { dzieciństwo miało smak czekolady } \\
& \text { i ananasów ze sklepu dziadka } \\
& \text { objęcia babci pachniały bzami } \\
& \text { dziadka tytoniem } \\
& \text { taty lawendą } \\
& \text { a mamy chanelem pięć }
\end{aligned}
$$

Z kolei zapachy i smaki wyniesione z późniejszych lat odzwierciedlają zabarwioną negatywną emocją, złą i niebezpieczną przestrzeń wojny:

$$
\begin{aligned}
& \text { potem zapanował zapach gruzu } \\
& \text { i kolejowych torów } \\
& \text { a gliniasty czarny chleb } \\
& \text { smakował jak ananas }
\end{aligned}
$$

${ }^{51}$ R. Jabłońska, Fragmenty, s. 20.

${ }^{52} \mathrm{Z}$ listu mailowego do autorki, 15.06.2015.

53 „Były [w Łodzi] parki, gdzie pachniały jaśminy i inne kwiaty. A zimą złe zapachy były przytłumione. Teraz Łódź ma zapach podobny do innych dużych miast (choć jeszcze są stare zapuszczone ulice «pachnące» jak dawniej)"; tamże.

${ }^{54}$ I. B. Kuźma, Łódź i jej etnograficzne eksploracje: doświadczenia - odkrycia - epifanie, [w:] Antropolog w mieście i o mieście, red. G. E. Karpińska, Wrocław-Łódź 2012, s. 119.

${ }^{55}$ Por.: M. S. Szczepański, W. Ślęzak-Tazbir, Miejskie pachnidło, s. 34. 


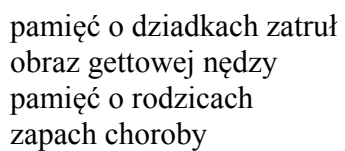

it 66-67; dawno

Zapach staje się depozytariuszem przeszłości także w wierszu zapach 2, w którym woń jabłek ${ }^{56}$ skojarzona została ze wspomnieniem skromnego mieszkania w powojennej Łodzi:

$$
\begin{aligned}
& \text { z drewnianej skrzynki pod łóżkiem } \\
& \text { sączy się ulubiony zapach } \\
& \text { kołysze mnie do snu } \\
& \text { to było życie całe temu w mojej } \\
& \text { klitce w kuchni w łódzkim domu } \\
& \text { zapach szarych renet } \\
& \text { którego już później nigdy } \\
& \text { nigdzie nie czułam }
\end{aligned}
$$

Wszystkie dobre i złe zapachy, które tworzą jakby złożoną z wielu różnych nut symfonię, pozostają na zawsze w zakamarkach pamięci, by tylko czasami powracać „w chwilach spokoju":

$$
\begin{aligned}
& \text { [...] } \\
& \text { gdy morze łagodnie obmywa } \\
& \text { piasek na plaży } \\
& \text { a słońce powoli opada } \\
& \text { zapachy i smaki dzieciństwa } \\
& \text { wracają nikłymi falami } \\
& \text { i dobre słone łzy } \\
& \text { spływają na wargi } \\
& \qquad \text { it } 66-67 \text {; dawno }
\end{aligned}
$$

Pisząc o zapachowej mapie miasta, trudno oddzielić ją od mapy wizualnej, słuchowej, taktylnej czy zwłaszcza smakowej. Blask oślepiającego słońca czy rażącego światła ulicznych lamp i neonów, ruch pędzących samochodów i śpieszących się przechodniów, uliczny gwar, hałas i głośna muzyka, a także zapachy orientalnych potraw i kwiatów, przenikają się wzajemnie. Ulotne, zmieniające się w czasie pejzaże zapachowe, które na równi z charakterystycznymi dla danego miasta widokami, dźwiękami i smakami tworzą koloryt lokalny, budują jednocześnie jego tożsamość.

${ }^{56}$ Zdaniem Mariana Bugajskiego, ,„pachnących owoców jest w polszczyźnie niewiele. Będą to przede wszystkim jabłka"; M. Bugajski, Jak pachnie rezeda?, s. 173.

${ }^{57}$ Wiersz napisany w 2015 r., dotąd nie publikowany.

${ }^{58}$ Związek wspomnień z zapachem i smakiem opisuje Marcel Proust: „kiedy [...] z dawnej przeszłości nic nie istnieje, wówczas jedynie zapach i smak, wątlejsze, ale żywsze, bardziej niematerialne, trwalsze, wierniejsze, długo jeszcze, jak dusze, przypominają sobie, czekają, spodziewają się - na ruinie wszystkiego - i dźwigają niestrudzenie na swojej znikomej kropelce olbrzymią budowlę wspomnień"; M. Proust, $W$ poszukiwaniu straconego czasu, t. 1. W stronę Swanna, przeł. T. Boy-Żeleński, Warszawa 1974, s. 58-59. 
Oswojenie się podmiotu z mapą olfaktoryczną miasta jest jednym z najważniejszych czynników, decydujących o zakorzenieniu w miejskiej przestrzeni. Zdaniem socjologów Marka S. Szczepańskiego i Weroniki Ślęzak-Tazbir zapachy, które poprzez rozbudzanie emocji „,budują specyficznie intymny związek pomiędzy miastem i mieszkańcami” i mają „wyjątkowo mocne powiązania z czymś, co wyrażamy w słowach «swojska atmosfera»”, powodują, że ,jesteśmy u siebie, że czujemy się zakorzenieni, że przestrzeń okazuje się dla nas gościnna" ${ }^{\text {"59 }}$.

W utworach poetyckich Renaty Jabłońskiej zapach — zarówno przyjemny, jak i brzydki - nie tylko bywa nastrojotwórczym elementem zmysłowego oglądu świata, ale jest także ważną częścią procesu autoidentyfikacji z otaczającą, miejską przestrzenią. Podczas gdy w kodzie zapachowym Tel Awiwu dominują intensywne wonie egzotycznych kwiatów ${ }^{60}$, wszechobecnych spalin, orientalnych potraw, morza i chamsinu, dawna Łódź kojarzy się z zapachem bzów i konwalii, jesiennych liści, smrodem zaniedbanych podwórek, a także aromatem przechowywanych w mieszkaniu jabłek. Mapa zapachowa obu miast konstytuuje ich odrębną geograficzno-kulturową tożsamość. $\mathrm{Z}$ drugiej strony, wyzwalając emocje i budząc wspomnienia trwalsze niż te generowane innymi zmysłami, zapach - choć efemeryczny — staje się spoiwem, które łączy odległe czasy i różne przestrzenie. Jak napisała bowiem amerykańska pisarka Helen Keller: „Węch jest potężnym czarownikiem, który przenosi nas przez tysiące mil i przez wszystkie lata naszego życia"61.

\section{LITERATURA}

D. Ackerman, Historia naturalna zmysłów, przeł. z ang. K. Chmielowa, Warszawa 1994;

P. C. Adams, Peripatetic Imagery and Peripatetic Sense of Place, [w:] Textures of Place: Exploring Humanist Geographies, red. P. C. Adams, S. D. Hoelscher, K. E. Till, Minneapolis 2001, s. 186-206;

Arystoteles, $O$ duszy, przeł. i oprac. P. Siwek, Warszawa 1988;

J. Barkai, Zatracona metropolia, przeł. V. Wein, Lublin 2013;

M. Bizan, Zapachy miast, Zeszyty Literackie 2010, nr 4, s. 130-133;

M. Bugajski, Jak pachnie rezeda?, Wrocław 2004;

S. Burkot, Polskie podróżopisarstwo romantyczne, Warszawa 1988;

Z. Chojnowski, Marzycielka z charakterem, Nowe Książki 2013 nr 3, s. 84 [rec.: R. Jabłońska, Dotyk, Tel Awiw, 2012];

C. Classen, D. Howes, A. Synnott, Aroma: the Cultural History of Smell, London-New York 2010

E. Czerniawska, J. M. Czerniawska-Far, Psychologia węchu i pamięci węchowej, Warszawa 2007;

M. Diaconu, The Rebellion of the "Lower" Senses: A Phenomenological Aesthetics of Touch, Smell, and Taste, www.o-p-o.net/essays/DiaconuArticle.pdf (dostęp: lipiec 2015);

Empire of the Senses: the Sensual Culture Reader, red. D. Howes, Oxford-New York 2006; Geographie des odeurs, red. R. Dulau, J.-R. Pitte, Paris 1998;

${ }^{59}$ M. S. Szczepański, W. Ślęzak-Tazbir, Miejskie pachnidło, s. 30, 31.

${ }^{60} \mathrm{~W}$ mikropowieści Leo Lipskiego Piotruś intensywniejący nocą zapach pomarańczy przybiera zwierzęcą postać, ewokując zarazem nastrój niepokoju i tajemnicy: „Fioletowa noc. Na peryferiach szakale. Ich żałosny śmiech. Kwitną przerażająco kwiaty pomarańczy. Zapach wychodzi o zmierzchu na ulicę, jak głodny wilk, i krąży niby krew, tętnicami”; L. Lipski, Piotruś, Olsztyn 1995, s. 72.

${ }^{61}$ H. Keller, Sense and Sensibility, [w:] The Smell Culture, s. 181; por.: D. Ackerman, Historia naturalna zmystów, przeł. z ang. K. Chmielowa, Warszawa 1994, s. 58. 
E. T. Hall, Ukryty wymiar, przeł. T. Hołówka, Warszawa 1976;

I. Henefeld-Ron, Wczorajsze jutro: wiersze z Izraela, Londyn 1979;

R. Jabłońska, Inny wymiar, Tel Awiw 2001;

-, Statyści, Gołdap 2008;

—, i tyle, wiersze wybrane, wybór, oprac. i posłowie B. Tarnowska, Gołdap 2010;

-, Dotyk, Tel Awiw 2012;

-, Skok, Tel Awiw 2013;

-, Fragmenty. Urywki wspomnień 1939-2009, Lublin 2014;

- inna, Gołdap 2015;

J. Jarzębski, Lódź-Tel Awiw, Tygodnik Powszechny 2002 nr 34, www.tygodnik.com.pl/numer/277234/jarzebski.html (dostęp: listopad 2015);

H. Keller, Sense and Sensibility, [w:] The Smell Culture Reader, red. J. Drobnick, Oxford-New York 2006, s. 181-183;

M. Kokoszka, Leśmian i magia zapachów, Białostockie Studia Literaturoznawcze 2013 nr 4, s. 277-287;

K. Kołodziej, Obraz Łodzi w piśmiennictwie pozytywistyczno-młodopolskim, Łódź 2009;

E. Konończuk, Geografia zapachów wobec dyskursów humanistyki, Białostockie Studia Literaturoznawcze $2013 \mathrm{nr}$ 4, s. 53-61;

A. Krupa, Aromaty i smrody. Olfaktoryczny pejzaż miasta, [w:] Lato w mieście. Różne oblicza kultury, red. R. Godula-Węcławowicz, Warszawa-Kraków 2010, s. 163-179;

D. Kulczycka, Obraz Ziemi Świętej w prozie polskiej doby romantyzmu, Zielona Góra 2012;

- W stronę Orientu: polscy i francuscy romantycy o Bliskim Wschodzie, Zielona Góra 2012;

E. Kuźma, Mit Orientu i kultury Zachodu w literaturze XIX i XX wieku, Szczecin 1980;

I. B. Kuźma, Lódź i jej etnograficzne eksploracje: doświadczenia - odkrycia - epifanie, [w:] Antropolog w mieście i o mieście, red. G. E. Karpińska, Wrocław — Łódź 2012, s. $117-$ 134;

M. Lewińska, Emigracji dzień pierwszy, Warszawa 1999;

L. Lipski, Piotruś, Olsztyn 1995;

K. Famulska-Ciesielska, S. J. Żurek, Literatura polska w Izraelu. Leksykon, Kraków-Budapeszt 2012;

K. E. Y. Low, Scents and Scent-Sibilities: Smell and Everyday Life Experiences, Cambridge 2009;

-, Olfactive Frames of Remembering: Notes on the Smells of Memories, Singapore 2007, http://socioblogsg.files.wordpress.com/2007/02/lowwp179.pdf; (dostęp: lipiec 2015).

Łódź, która przeminęła w publicystyce i prozie (antologia), red. P. Boczkowski, Łódź 2008;

A. Marchlewska-Koj, Węch w życiu człowieka, www.if-pan.krakow.pl/ptp/6.html (dostęp: lipiec 2015);

M. Michalska-Suchanek, Zapach jako kategoria poetyki. Na materiale nowelistów rosyjskich lat 80. XIX wieku, Slavia Orientalis $1995 \mathrm{nr}$ 4, s. 527-542;

Myśleć po polsku, myśleć po hebrajsku - z Renata Jabłońska rozmawia Beata Tarnowska, Fraza $2008 \mathrm{nr} 3 / 4$, s. $46-54$.

B. Mytych-Forajter, Czule punkty Grochowiaka. Szkice i interpretacje, Katowice 2010;

J. Petrowicz, Fale tkliwości i żalu, Nowe Książki 2010 nr 9, s. 69 [rec.: R. Jabłońska, i tyle, Gołdap, 2010];

K. Piątkowska, $W$ zasięgu wzroku, stuchu lub węchu. O pewnych faktach spoteczno-kulturowych $z$ europejskiej historii, antropologicznych konstatacjach oraz impresjach z kultury lokalnej dużego, polskiego miasta, czyli o kodach niezsynchronizowanych, zew.info.pl/files/piatkowska17.pdf (dostęp: maj 2015);

S. Pink, Zwiedzanie miasta. Sensoryczny charakter więzi spolecznych w etnograficznym procesie wytwarzania miejsca, przeł. M. Songin, Tematy z Szewskiej 2011 nr 1 (5), s. 137-148;

D. Porteous, Smellscape, [w:] The Smell Culture Reader, red. J. Drobnick, Oxford-New York 2006, s. 89-106;

M. Proust, W poszukiwaniu straconego czasu, t. 1. W stronę Swanna, przeł. T. Boy-Żeleński, Warszawa 1974;

P. Rodaway, Sensuous Geographies: Body, Sense and Place, London-New York 1994; 
E. Rybicka, Geopoetyka. Przestrzeń i miejsce we wspótczesnych teoriach i praktykach literackich, Kraków 2014;

-, Modernizowanie miasta. Zarys problematyki urbanistycznej w nowoczesnej literaturze polskiej, Kraków 2003;

E. W. Said, Orientalizm, przeł. W. Kalinowski, wstęp Z. Żygulski, Warszawa 1991;

J. Schlör, Tel Aviv: From Dream to City, przeł. z niem. H. Atkins, London 1999;

G. Simmel, Most i drzwi: wybór esejów, przeł. M. Łukasiewicz, Warszawa 2006;

L. Skompska, Za ruchoma przegroda, Tygiel Kultury 2002 nr 7-9, s. 179 [rec.: R. Jabłońska, Chamsin, Olsztyn 2002];

J.-F. Staszak, W stronę geografii zapachów, tłum. z franc. E. Konończuk, Białostockie Studia Literaturoznawcze $2013 \mathrm{nr}$ 4, s. 41-51;

P. Süskind, Pachnidto, przeł. z niem. M. Łukasiewicz, Warszawa 2015;

M. S. Szczepański, W. Ślęzak-Tazbir, Miejskie pachnidło. Fragmentacja i prywatyzacja przestrzeni w perspektywie osmosocjologicznej, Studia Regionalne i Lokalne $2008 \mathrm{nr} 2$ (32), S. $18-40$;

A. Wieczorkiewicz, Apetyt turysty. O doświadczaniu świata w podróży, Kraków 2012;

J. Winczakiewicz, Izrael w poezji polskiej. Antologia, Paryż 1958;

Ziemia Święta w dobie romantyzmu: antologia, oprac. D. Kulczycka, Zielona Góra 2013.

HOW DOES TEL AVIV (AND LÓDŹ) SMELL? ABOUT OLFACTORY SPACE IN RENATA JABLOŃSKA'S POETRY

The experience of a city, as any other space, is always multisensory. The smells specific to particular locations not only create their identity in a specific manner but are also part of the individual's process of self-identification with the surrounding space. A new research perspective, consisting in the study of sensual spaces in literature in the totality of visual, audial, tactile, olfactory and even gustatory sensations, allows a more complete interpretation of the spatial dynamic of the presented locations. The article analyses Renata Jabłońska's exploration of her current place of residence-Tel Aviv, Israel, in combination with her hometown of Łódź, Poland, as olfactory spaces. Both spaces often go together since Telavivian smells bring to the poet's mind the smells of her early youth.

KEYWORDS: Renata Jabłońska; Polish-Israeli literature; olfactory space; Tel Aviv; Łódź; geopoetics. 